\title{
Evaluation of use waste aluminum on the burning of solid rocket propellant
}

\author{
Rafaela Baldissera $^{\# 1}$, Victor L. B. Khün, Francisco Telöken ${ }^{\# 1}$,Juliano Carteri ${ }^{\# 1}$, \\ Matheus Poletto ${ }^{\# 2}$
}

\#1 Engineering and Exact Science, University of Caxias do Sul, Rio Grande do Sul, Brazil

\#2 Post-Graduate Program in Engineering of Processes and Technologies (PGEPROTEC),

Engineering and Exact Science, University of Caxias do Sul, Rio Grande do Sul, Brazil

\section{ABSTRACT}

Solid propellants based on potassium nitrate $\left(\mathrm{KNO}_{3}\right)$ and sucrose are widely used in rocketry, because they are inexpensive and easily obtainable compounds and also generate high specific thrust. In this study, the performance of propellants based on a mixture of 65 $\mathrm{wt} \% \mathrm{KNO}_{3}$ and $35 \mathrm{wt} \%$ sucrose, named $\mathrm{KNSu}$, was evaluated.Aluminum waste particles were loading at $2.5 \mathrm{wt} \%, 5 \mathrm{wt} \%$ and $7.5 \mathrm{wt} \%$. Aluminum was used as a powder with an average particle size of $35 \mu \mathrm{m}$. Rocket engines were developed and the thrust versus time curves obtained for the samples studied. The results showed that the utilization of $5 \mathrm{wt} \%$ caused a $30 \%$ increase in both the specific impulse and the average gas ejection velocity when compared to KNSu. The incorporation of $2.5 \mathrm{wt} \%$ and $7.5 \mathrm{wt} \%$ caused a reduction in the specific impulse and other properties evaluated when compared to KNSu. Based on the results obtained, it is possible to state that the insertion of aluminum waste from the metalworking industry may contribute to the increase of the performance of rockets that use KNSu as a solid propellant.

Key words:Rocket, aluminum, burning properties, thrust, total impulse.

Corresponding Author:Matheus Poletto (mpolett1@ucs.br)

\section{INTRODUCTION}

Solid propellants are commonly used for rocket propulsion, space vehicles, military artifacts, among other applications (Chaturvedi and Dave, 2015; Baldissera et al., 2016). A solid propellant normally consists of a mixture of oxidizing and reducing agents, that when ignited, are consumed and release a large amount of energy (Scimareli, et al., 2002; Soares et al., 2018). The combustion products are gases formed by low molar mass molecules, which contribute to the increase in temperature and pressure inside the rocket engine chamber, besides solid residues and the energy released. When these gases reach the exit of the rocket engine they encounter a converging-divergent nozzle through which these gases exit accelerated, resulting in rocket thrust (Scimareli, et al., 2002).

In the development of solid propellants a number of chemical constituents as well as different proportions between these constituents are used. As a result, propellant performance is also altered due to differences in physical and chemical properties observed during combustion. The solid propellant obtained from the mixture of sucrose and potassium nitrate, called KNSu, is generally used in rocketry. The choice of this propellant is based on the ease of obtaining its components as well as their preparation. In addition, KNSu preparation is a 
safe handling process and this propellant also promotes relatively high specific impulse compared to black powder (Foltran et al., 2015). In general, KNSu consists of a mixture of 65 $\mathrm{wt} \%$ of potassium nitrate and $35 \mathrm{wt} \%$ of sucrose.Additives in the basic formulation of $\mathrm{KNSu}$ are commonly used to increase the specific thrust of this propellant. Additives such as metal oxides and metals are widely used (Chaturvedi and Dave, 2015; Aziz et al., 2015). The oxides used are iron oxide and also magnesium oxide. Several metallic additives can be used, such as, beryllium, magnesium, zirconium and aluminum (Aziz et al., 2015; Zhou et al., 2019).

When compared to other metallic additives aluminum is vastly used due to the high energy released during its combustion, low cost and low toxicity (Aziz et al., 2015). However, some disadvantages with the use of this additive are also reported in the literature, such as the formation of particle agglomerates (Xiao, et al., 2019) and the formation of an oxide layer on the metal surface (Griego, Yimaz and Atmanli, 2019), both factors reduce additive performance when incorporated into rocket propellants. Thus, the present work aims to evaluate the effect of the incorporation of different loadings of aluminum wastes on the performance of KNSu. Parameters such as mean thrust, mean gas ejection velocity, and specific thrust were evaluated on a horizontal static test bench.

\section{METHODOLOGY}

The fertilizer used as a potassium nitrate source was Krista $\mathrm{B}{ }^{\circledR}$ produced by the manufacturer Yara Brazil. Refined sugar was purchased from a local market. The $35 \mu \mathrm{m}$ particle diameter aluminum residue comes from a metalworking industry from Caxias do Sul/Brazil.

Potassium nitrate was obtained through the recrystallization process of the fertilizer. Thus, $1 \mathrm{~kg}$ of fertilizer was dissolved in $1 \mathrm{~L}$ of water and the mixture was heated to boiling under constant manual agitation. After, the mixture was filtered and cooled in a freezer at $0^{\circ} \mathrm{C}$ to start crystal formation. After $4 \mathrm{~h}$ of cooling the supernatant was discard and moisture was removed from the potassium nitrate crystals by heating at $100^{\circ} \mathrm{C}$ in a heating plate (Baldissera and Poletto, 2018).

Purified potassium nitrate was mixed with refined sugar in a proportion of $65 \mathrm{wt} \%$ and 35 wt $\%$, respectively. The contents of $2.5 \%, 5 \%$ and $7.5 \%$ of aluminum waste were incorporated into the initial mixture. After that, $1 \mathrm{~L}$ of water was added and the mixture was heated at $100^{\circ}$ $\mathrm{C}$ and kept under constant manual stirring until a solid mass formed. The obtained propellant was cooled in a desiccator and then ground in a roller mill to a particle size of less than 125 $\mu \mathrm{m}$. A mass of $6.3 \mathrm{~g}$ of propellant was then placed in a mould and 5 tons of pressure was used in a hydraulic press for moulding the propellant grain.

The propellant grain was inserted into the rocket engine produced according to the dimensions shown in Figure 1. The rocket motor was developed using glue and $\mathrm{Kraft} \circledast$ paper. The paperwas soaked in glue and wrapped in several layers to obtain the dimensions showed in Figure 1. The nozzle was constructed from a mould using epoxy resin. To evaluate the performance of each formulation the mean thrust, average gas ejection velocity, total thrust and specific thrust were calculated (Sutton and Biblarz, 2001) from the thrust versus time curves obtained from a horizontal static test bench. 


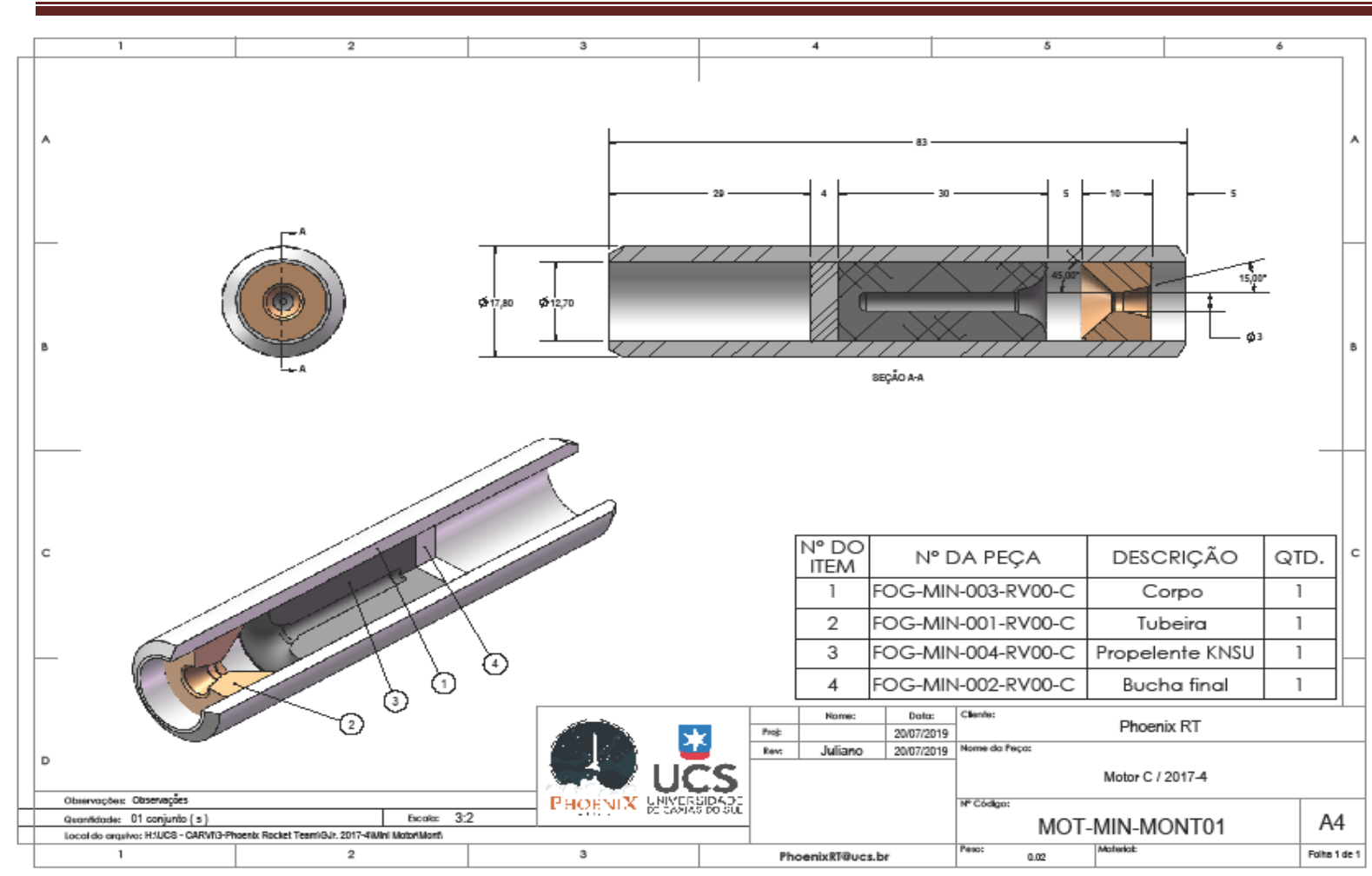

Fig 1: Rocket motor for propellant test

The static test bench, shown in Figure 2, was used to obtain the thrust versus time curves. The bench is equipped with a $20 \mathrm{~N}$ load cell with data acquisition system. For each formulation developed three rocket engines were tested.

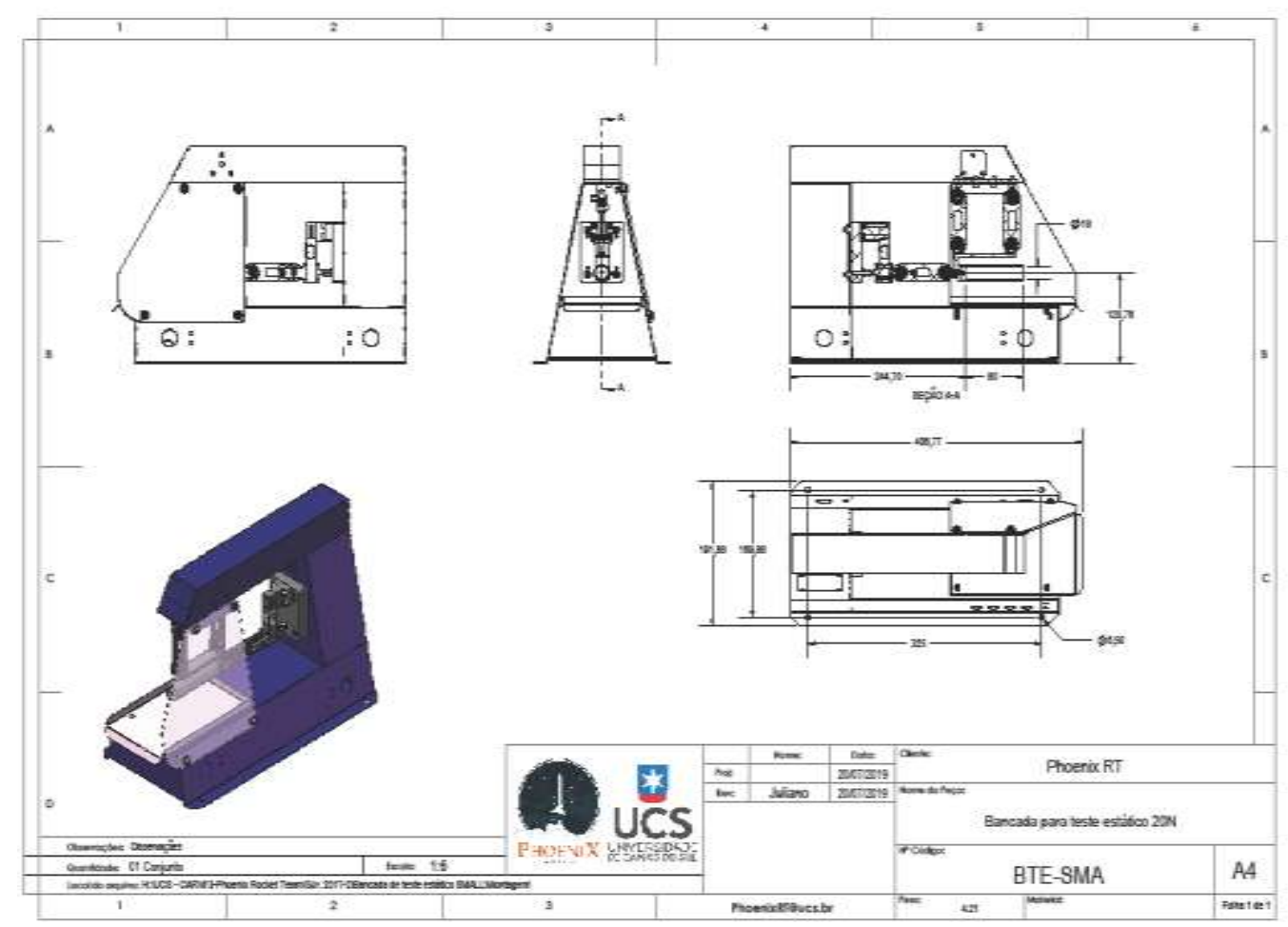

Fig 2: Static test bench 


\section{RESULTS AND DISCUSSION}

The thrust versus time curves obtained for the KNSu and also for the samples with $\mathrm{Al}$ particles are shown in Figure 3. It is observed that the addition of $2.5 \mathrm{wt} \%$ and $7.5 \mathrm{wt} \%$ of Al residues caused the reduction in thrust generated by propellant burning when compared to $\mathrm{KNSu}$. On the other hand, the insertion of $5 \mathrm{wt} \%$ improved propellant performance when compared to KNSu.

The insertion of $\mathrm{Al}$ particles provides an increase in the burning time for all samples evaluated. According to the literature, the main product of $\mathrm{Al}$ combustion is aluminum oxide, which is formed from the condensation of aluminum suboxides formed during propellant combustion (Beckstead, 2002). One fraction of the oxide formed deposits on the surface of the Al particle, causing a particle burn barrier, while the other fraction of the oxide is transported out of the engine chamber as a metallic smoke (Beckstead, 2002). The oxide deposited on the surface of the $\mathrm{Al}$ particle reduces the burning rate of this particle and thereby increases the propellant burning time (Beckstead, 2002).

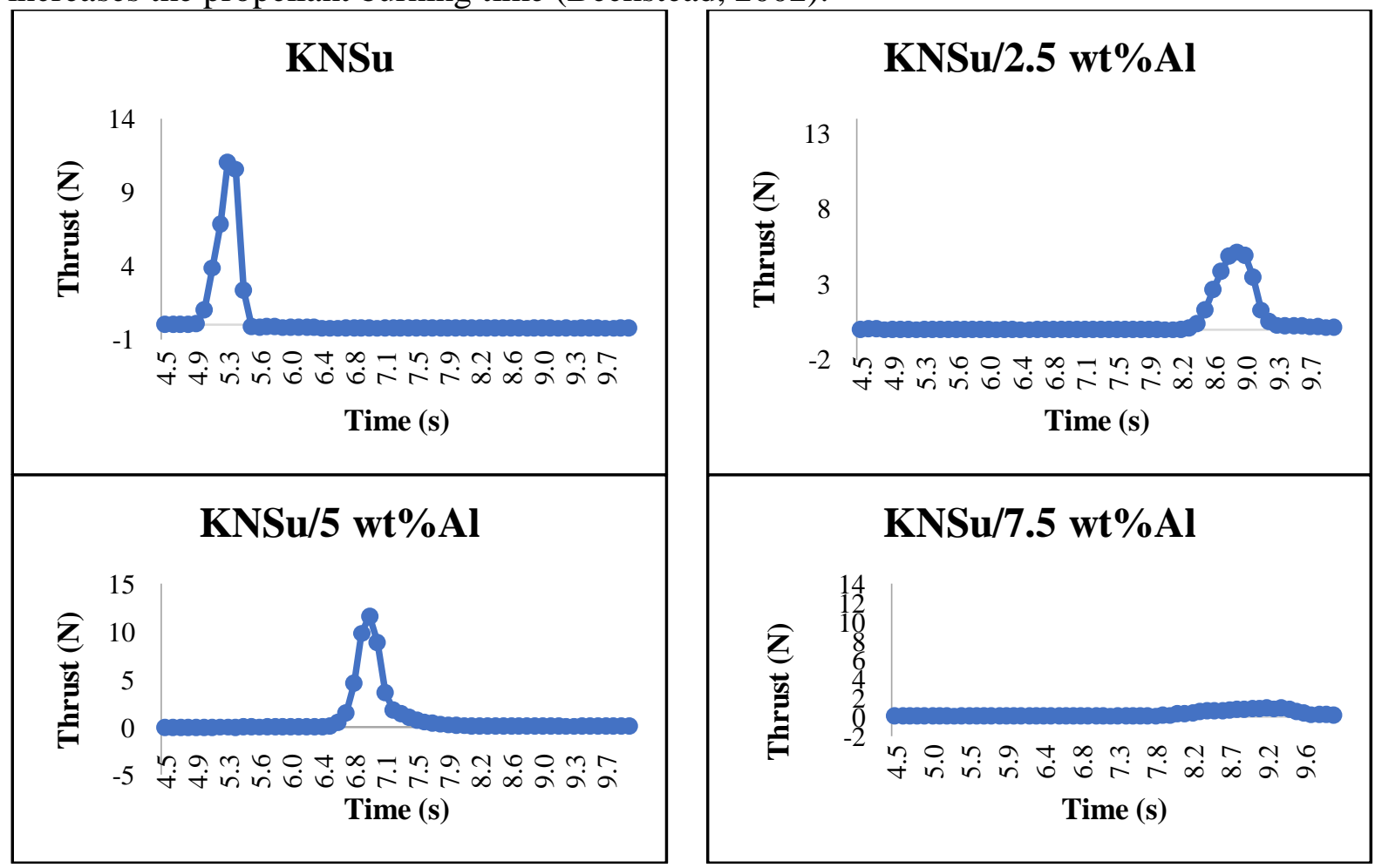

Fig 3: Thrust versus time curves obtained for the rocket motors tested

Table 1 shows the total thrust (It), mean thrust (Tmean), average gas ejection velocity (c) and specific thrust (Is) values obtained from the triplicate analysis of rocket engine performance developed from the KNSu and KNSu formulations with $\mathrm{Al}$ residues.

Table1. Burning parameters obtained for the samples tested.

\begin{tabular}{|c|c|c|c|c|c|}
\hline Samples & Unit & $\mathrm{KNSu}$ & $\mathrm{KNSu} / 2.5 \mathrm{wt} \% \mathrm{Al}$ & $\mathrm{KNSu} / 5 \mathrm{wt} \% \mathrm{Al}$ & $\mathrm{KNSu} / 7.5 \mathrm{wt} \% \mathrm{Al}$ \\
\hline $\mathrm{It}$ & $\mathrm{Ns}$ & $3.30 \pm 0.87$ & $2.59 \pm 0.08$ & $4.28 \pm 0.07$ & $1.24 \pm 0.21$ \\
\hline $\mathrm{T}_{\text {mean }}$ & $\mathrm{N}$ & $4.46 \pm 0.67$ & $1.94 \pm 0.14$ & $3.20 \pm 0.73$ & $0.32 \pm 0.34$ \\
\hline $\mathrm{c}$ & $\mathrm{m} / \mathrm{s}$ & $524.44 \pm 3.16$ & $411.46 \pm 1.37$ & $678.98 \pm 1.19$ & $196.79 \pm 3.33$ \\
\hline $\mathrm{Is}$ & $\mathrm{s}$ & $53.51 \pm 2.67$ & $41.99 \pm 1.40$ & $69.28 \pm 1.22$ & $20.08 \pm 3.40$ \\
\hline
\end{tabular}


As can be seen from Table 1, the formulation that presented the best performance was the one with the insertion of $5 \mathrm{wt} \%$ of $\mathrm{Al}$ residues. The increase in the average gas ejection velocity and also in the specific impulse of the sample with $5 \mathrm{wt} \%$ of Al was approximately $30 \%$ when compared to KNSu. The addition of $2.5 \mathrm{wt} \%$ did not have a synergistic effect with $\mathrm{KNSu}$, thus reducing propellant performance. The reduction in total thrust was over $27 \%$, while average thrust fell over $50 \%$.

The $7.5 \mathrm{wt} \%$ content of $\mathrm{Al}$ wastes led to a further reduction of the evaluated parameters. This result shows that higher levels of incorporation of the residue are not indicated. This reduction in propellant performance may be associated with the formation of solid residues during propellant burning, such as aluminum oxide $\left(\mathrm{Al}_{2} \mathrm{O}_{3}\right)$ (Griego, Yimaz and Atmanli, 2019), as well as ejection of inorganic particles that could be contaminated Al particles, as this material is waste from a industrial process. When the $\mathrm{Al}$ residue incorporation increases these combined phenomena can cause rocket motor instability reducing propellant performance. Another factor to consider is that the epoxy resin, which was used for the construction of the nozzle, may eventually melt due to increased temperature in the engine chamber thus increasing the throat diameter which would result in reduced rocket motor performance. Figure 4 visually compares the difference in propellant performance with the addition of $5 \mathrm{wt} \%$ and $7.5 \mathrm{wt} \%$ of $\mathrm{Al}$ residues.

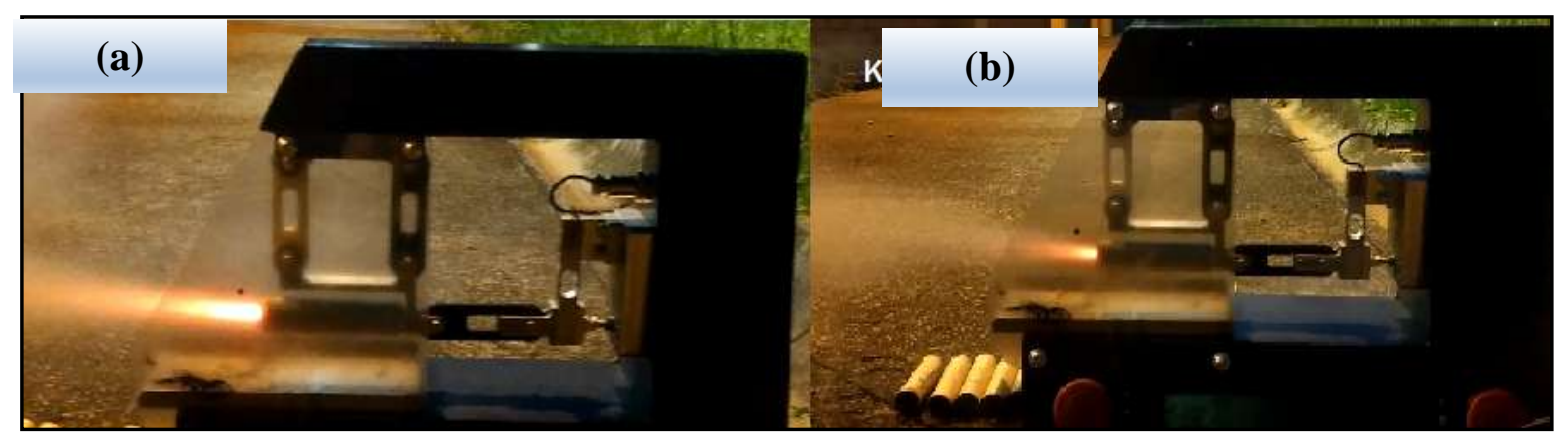

Fig4:Static test of samples with $5 \mathrm{wt} \%$ (a) and $7.5 \mathrm{wt} \%$ (b) Al residues

According to the classification proposed by the National Association of Rocketry (NAR) rocket engines developed with $\mathrm{KNSu}, 2.5 \mathrm{wt} \% \mathrm{Al}$ and $5 \mathrm{wt} \% \mathrm{Al}$ can be classified as Class B with a total impulse between 2.51 and $5.00 \mathrm{~N} \mathrm{~s}$ (NAR, 2019). On the other hand, the rocket engine's performance with $7.5 \mathrm{wt} \%$ of $\mathrm{Al}$ wastecan be classified as Class A with a total impulse of 1.26 to $2.5 \mathrm{~N}$ s.

\section{CONCLUSION}

The insertion of $\mathrm{Al}$ particles in the performance of KNSu solid propellants was evaluated. The results showed that the addition of $\mathrm{Al}$ residue caused an increase in the burning time of all studied formulations due to the formation of an aluminum oxide film on the Al particle surface, which reduces its burning rate. The addition of $5 \mathrm{wt} \%$ of aluminum waste proved to be the most suitable formulation, resulting in a $30 \%$ increase in specific impulse and also in the average gas ejection velocity when compared to KNSu. Incorporation levels higher than $7.5 \mathrm{wt} \%$ were not adequate due to the marked reduction of the evaluated properties. The insertion of aluminum waste from the metalworking industry has generated promising results that may contribute to the increased performance of rockets using KNSu as a solid propellant. However, studies using a nanometer-scale material of higher purity as well as computational simulations are still needed to better evaluate the use of $\mathrm{Al}$ as an additive in KNSu-based solid propellants. 


\section{ACKNOWLEDGMENTS}

The authors are grateful to the University of Caxias do Sul and the organization commission of the II Congresso Aeroespacial Brasileiro.

\section{REFERENCES}

1. Aziz, A., Mamat, R., Ali, W.K.W. e Perang, M.R.M., (2015). "Review on typical ingredients for ammonium perchlorate based solid propellant". ARPN Journal of Engineering and Applied Sciences, Vol. 10, No. 15, p. 6188-6191.

2. Baldissera, R. e Poletto, M., (2018). "Solid propellants for rockets: a methodology to obtain high purity $\mathrm{KNO}_{3}$ from an inexpensive source". International Journal of Research in Engineering and Technology, Vol. 7, No. 9, p. 52-56.

3. Baldissera, R., Soares, D.M., Gedoz, T.B., Morelatto, T., Severo, T.C. e Poletto, M., (2016). "Evaluation of rocket propulsion performance using potassium nitrate/sucrose and aluminum/ice as propellants". Journal of Basic and Applied Research International, Vol. 19, No. 3, p. 152-156.

4. Beckstead, M.W. (2002). "A summary of aluminum combustion." Internal Aerodynamics in Solid Rocket Propulsion, Rhode-Saint-Genèse, Bélgica.

5. Chaturvedi, S. e Dave, P.N., (2015). "Solid propellants: AP/HTPB composites propellants". Arabian Journal of Chemistry, DOI: 10.1016/j.arabjc.2014.12.033.

6. Foltran, A.C., Moro, D.F., da Silva, N.D.P., Ferreira, A.E.G., Araki, L.K. e Marchi, C.H., (2015). "Burning rate measurement of $\mathrm{KNSu}$ propellant obtained by mechanical press". Journal of Aerospace Technology and Management, Vol. 7, No. 2, p. 193-199.

7. Griego, C., Yilmaz, N. e Atmanli, A., (2019). "Analysis of aluminum particle combustion in a downward burning solid rocket propellant". Fuel, Vol. 237, p. 405412.

8. NAR. National Association of Rocketry. Disponível em <https://www.nar.org/>. Acesso jun. 2019.

9. Scimareli, J., Koyama, M.F., Teixeira, J.M. e Iha, K., (2002). "Propelente sólido compósito polibutadiênico: I- influência do agente de ligação". Química Nova, Vol. 25, No. 1, p. 107-110.

10. Soares, D.M., Telöken, F., Severo, T.C., Poletto, M. "Development of a vertical static test bench for amateur rocket engines". International Journal of Advanced Scientific and Technical Research, Vol. 5. No 8, p. 45-49.

11. Sutton, G.P. e Biblarz, O. (2001)." Rocket Propulsion Elements". Wiley Interscience, New York, USA, $7^{\text {a }}$ edition.

12. Carter, M.G., 2008. An investigation into the combustion and performance of small solid propellant rocket motors. Final Thesis Report. University of New South Wales. New South Wales, Australia.

13. Xiao, L., Pang, W., Qin, Z., Li, J., Fu, X., e Fan, X. (2019). "Cluster analysis of Al agglomeration in solid propellant combustion". Combustion and Flame, Vol. 203, p. 386-396.

14. Zhou, S., Tang, G., Pang, A., Guo, X., Wu, F., Song, H., Xu, X., Hu, X., Wang, Y. "Synthesis of an alkynyl neutral polymer-bonding agent and its enhancing effect on tensile strength of glycidyl azide polymer-based propellants". Iranian Polymer Journal, https://doi.org/10.1007/s13726-019-00756-w 